\title{
Desalination of Seawater by Liquid Columns and Decompression Boiling (Recovery of Condensation Latent Heat)
}

\author{
Toshihiko Shakouchi \\ Graduate School of Engineering, Mie University, Tsu-shi, Japan \\ Email: shako@mach.mie-u.ac.jp
}

How to cite this paper: Shakouchi, T. (2018) Desalination of Seawater by Liquid Columns and Decompression Boiling (Recovery of Condensation Latent Heat). Journal of Water Resource and Protection, 10, 809-816.

https://doi.org/10.4236/jwarp.2018.108046

Received: June 12, 2018

Accepted: August 21, 2018

Published: August 24, 2018

Copyright $\odot 2018$ by author and Scientific Research Publishing Inc. This work is licensed under the Creative Commons Attribution International License (CC BY 4.0).

http://creativecommons.org/licenses/by/4.0/

\begin{abstract}
In this study, the concept of a new seawater desalination method and equipment using liquid columns of seawater and desalinated fresh water, decompression boiling and evaporation, condensation, and recovery of condensation latent heat are proposed. The equipment consists of seawater and freshwater columns approximately $10 \mathrm{~m}$ high with top spaces. The pressure of the top space, the evaporation and condensation area, of the seawater column, for example, is reduced approximately $30 \mathrm{mmHg}$ (abs.) using the seawater column, after which it is heated from the general seawater temperature of $25^{\circ} \mathrm{C}$ to $30^{\circ} \mathrm{C}$ to boil and evaporate the seawater. The vapor is cooled by the seawater at approximately $25^{\circ} \mathrm{C}$ in a heat exchanger, and then, it is condensed and sent to the fresh water column. At this time, the condensation latent heat is recovered to preheat the newly flowing seawater. The evaporation or condensation rate, namely, the production rate of freshwater, by the new desalination equipment is also estimated by the results of the existing quadruplex effect vacuum evaporator used in the salt production industry. This new desalination method and its associated equipment also can be used to purify polluted water and waste water.
\end{abstract}

\section{Keywords}

New Desalination Method of Seawater, Liquid Column, Decompression Boiling, Evaporation and Condensation, Recovery of Condensation Latent Heat

\section{Introduction}

There is a huge amount of water in the world, but available fresh water is only a 
few percent of it. Recently, the lack of fresh water has become a serious problem globally. One of the practical solutions is the desalination of seawater, for which there are several methods including evaporation, membrane, and freezing methods. In recent decades, the membrane method has been developed, improved, and widely used because of its low operating costs compared to other methods. Currently, approximately $40 \%, 50 \%$ and $5 \%$ of the desalination of seawater is accomplished using evaporation, membrane or reverse osmotic (RO) membrane, and electro dialysis-methods, respectively. For example, in Saudi Arabia, one million cubic meters per day, $1 \times 10^{6} \mathrm{~m}^{3} /$ day, of fresh water is produced from seawater by the multistage flash vaporization method and in Israel $3.3 \times$ $10^{5} \mathrm{~m}^{3} /$ day is produced by the RO membrane-method. However, lower construction, operating, and maintenance costs are needed [1].

A desalination system by decompression-boiling using a liquid column of about $10 \mathrm{~m}$ in height [2] [3] has been proposed, but in their system condensation latent heat did not recover and the desalination performance seems to be not enough.

In particular, Goswami et al. [2] [4] studied this a lot, but it seems that it has not been put to practical use.

In this study, the concept of a new seawater desalination method and equipment by decompression boiling and evaporation of seawater using a liquid column of about $10 \mathrm{~m}$ high and the heat exchanger to condensate the evaporation vapor and recover the latent heat is proposed [5], and the performance and the feasibility are also verified by using the previous data [6] [7] [8] for the vacuum evaporator of salt production from seawater.

The equipment consists of seawater and freshwater columns approximately 10 $m$ high. The pressure of the top space, the evaporation and condensation area, of the seawater column, is reduced to approximately $30 \mathrm{mmHg}$ (abs.) using the seawater column, after which it is heated a little from the general seawater temperature of $25^{\circ} \mathrm{C}$ to $30^{\circ} \mathrm{C}$ to boil and evaporate the seawater. The vapor is cooled by the seawater at approximately $25^{\circ} \mathrm{C}$ in a heat exchanger, and then, it is condensed and sent to the freshwater column. At this time, the condensation latent heat is recovered to preheat newly flowing seawater.

This process is repeated, and freshwater is produced almost all automatically. The evaporation or condensation rate, namely, the production rate of freshwater, by the new desalination equipment is also estimated by the results of the existing quadruplex effect vacuum evaporator used in the salt production industry (Naikai Salt Ind. Co., Ltd., Japan, 2006).

This new desalination method and its associated equipment also can be used to purify polluted water and waste water.

\section{Desalination of Seawater}

Seawater can be desalinated using the evaporation method by phase change, the freeze method, and the membrane method. The evaporation methods include 
the multistage flash vaporization, a multiple effect vacuum evaporator, and the steam compression methods.

The relationship between the saturated vapor pressure $p_{s}$ and the temperature $t_{s}$ of seawater must be known.

Figure 1 shows the relationship between the pressure $p_{s}[\mathrm{mmHg}$ (abs.)] and the temperature $t_{s}\left[{ }^{\circ} \mathrm{C}\right]$ of the evaporation water and the seawater at a salt level of approximately 3 [\%]. $p_{s}$ increases with increasing $t_{s}$, and their relationship can be expressed by for evaporation water:

$$
p_{s}=0.0006 t_{s}^{3}+0.0444 t_{s}^{2}-4.639 t_{s}+129.66
$$

for seawater of $3 \%$ concentration:

$$
p_{s}=0.0015 t_{s}^{3}-0.149 t_{s}^{2}+6.78 t_{s}-83.05
$$

In addition, for seawater $p_{s}$ is about $40\left[\mathrm{mmHg}\right.$ (abs.)] when $t_{s}$ is approximately $35\left[{ }^{\circ} \mathrm{C}\right]$.

\section{New Seawater Desalination Method and Equipment (by Decompression Boling Using Liquid Column and Seawater)}

Figure 2(a) shows the schematic diagram of the new seawater desalination equipment. Freshwater is produced after evaporating seawater under decompression at approximately 40 [mmHg (abs.)] by liquid, seawater, column and then cooling the vapor by a heat exchanger and seawater of temperature at approximately $T_{\text {sea }}=25\left[{ }^{\circ} \mathrm{C}\right]$.

\section{* Operation procedure;}

The seawater column 10 in Figure 2 (a) of height $H_{1} \approx 10[\mathrm{~m}]$ is set vertically in the Seawater tank 1 filled with seawater.

First, the Valves 2 and 3 mounted on the Seawater column 10 are closed and

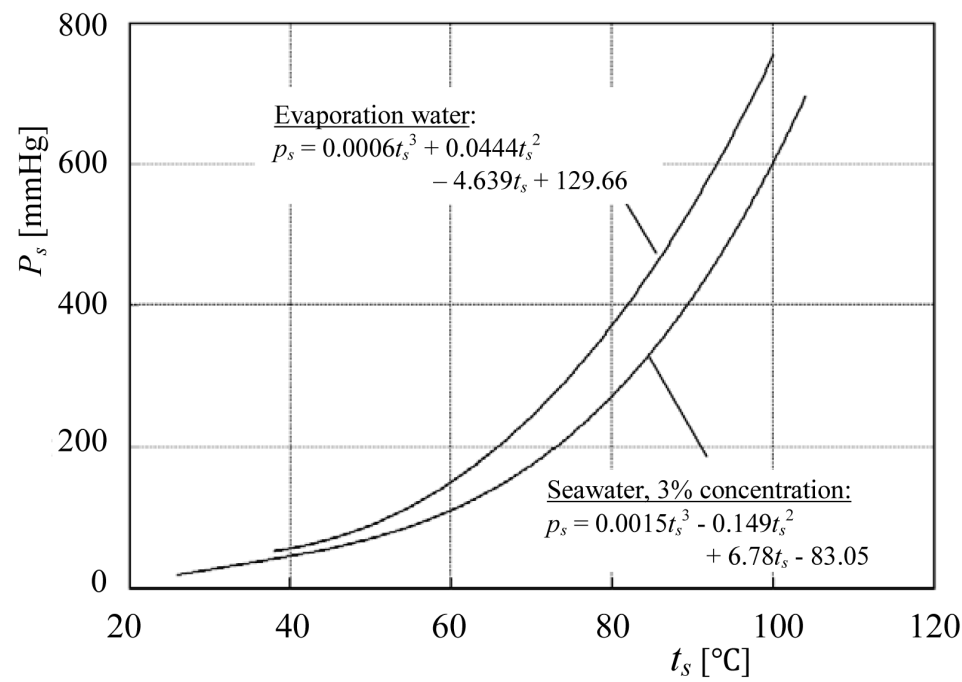

Figure 1. Vapor pressure of evaporation water and seawater [The Society of Sea Water Science, Japan (1974)]. 


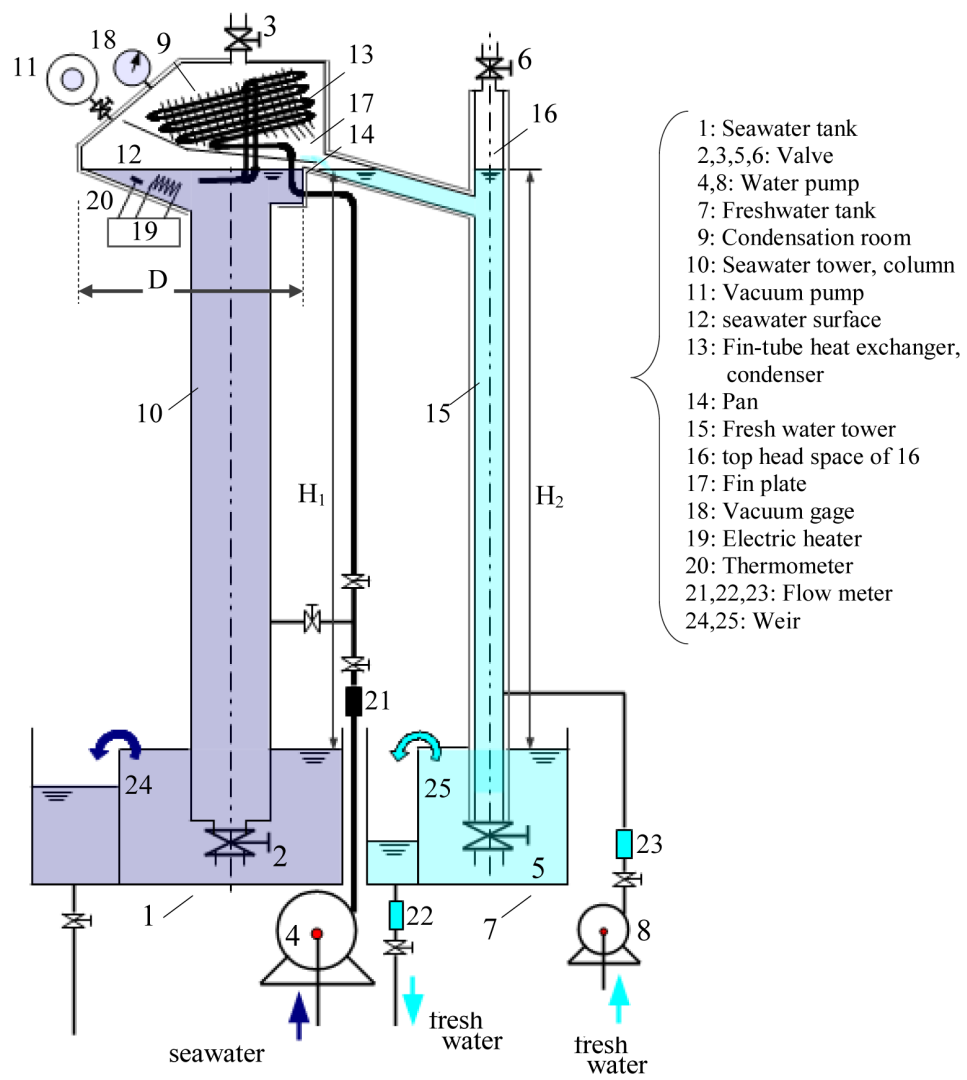

(a)

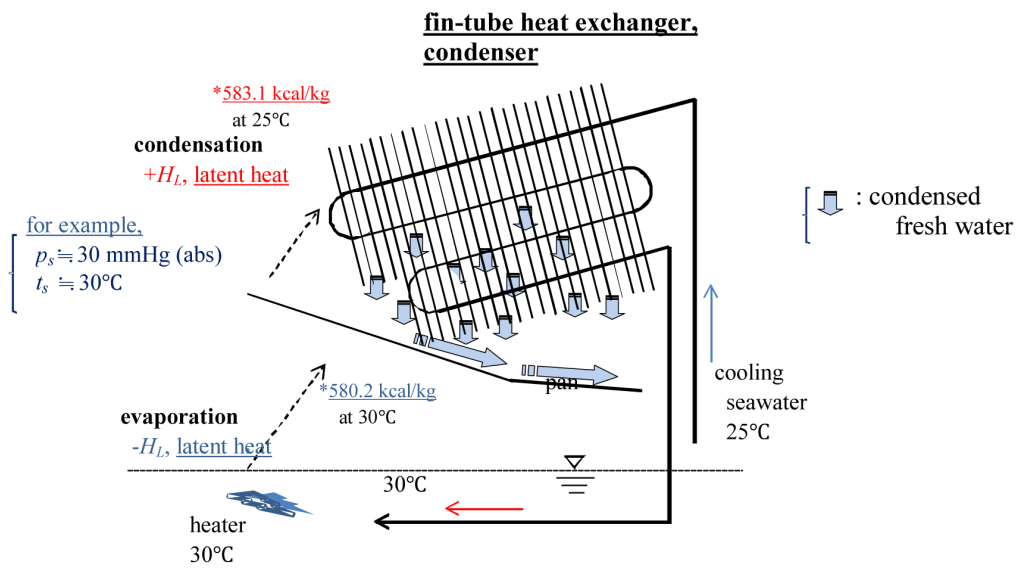

(b)

Figure 2. New seawater desalination equipment concept. (Drawing in the Japanese patent, No. 5398046, Shakouchi, 2011). (a) Schematic diagram of a new seawater desalination equipment; (b) Details of condenser in top space, evaporation and condensation areas.

opened, respectively, and the column is filled with seawater by the Pump 4.

Next, the Valves 5 and 6 are closed and opened, respectively, and the Fresh water column 15 of height $H_{2} \approx 10$ [m], which is set vertically in the Freshwater tank 7, is filled with freshwater by the Pump 8.

Opening the Valves 2 and 5 after closing the Valves 3 and 6 yields a negative 
pressure in the upper space of each column approximating that a vacuum.

If the pressure in the Evaporation and condensation room 9 at the top of the seawater column is set to approximately $p_{s t}=30[\mathrm{mmHg}$ (abs.)] by the Vacuum pump 11, and the temperature near the seawater surface 12 is set to approximately $T_{s}=30\left[{ }^{\circ} \mathrm{C}\right.$ ] by the Heater 19 , the seawater boils and evaporates. In Figure 2 (b), the details of the top area, evaporation and condensation areas, including fin-tube heat exchanger, condenser, and the conditions of evaporation and condensation, for example, $p_{s t} \approx 30[\mathrm{mmHg}(\mathrm{abs})],. T_{s} \approx 30\left[{ }^{\circ} \mathrm{C}\right]$, and $T_{\text {sea }}$ $\approx 25\left[{ }^{\circ} \mathrm{C}\right]$, are shown.

Freshwater is obtained by cooling and condensing the vapor by the Heat exchanger 13 with seawater at approximately $25\left[{ }^{\circ} \mathrm{C}\right]$. The freshwater is collected on the Pan 14 and is introduced to the Fresh water column 15. At that time, the evaporation latent heat is collected as the condensation latent heat and is used to preheat the cooling seawater. The pressures and water levels in both the top head areas, 9 and 16, are maintained constants because the flow rate of cooling the seawater is equal to the evaporation rate. The sea water corresponding to the evaporation-condensation rate is introduced into the Condensation room 9 automatically through the heat exchanger tube from the suction port of the Pump 4. The new desalination method, system, includes a heat exchanger, condenser in the head space of the seawater tower and the desalination can be operated continuously under a small control of the pressure and temperature in the evaporation and condensation room 9, and this method which boils seawater at a low temperature and also condenses the vapor will produce freshwater inexpensively compared to other seawater desalination methods because of the simple and rational arrangements to recover the latent heat. But, the cost performance of this method has to be examined precisely.

\section{Evaporation and Condensation Rates (Freshwater Rate)}

Using the results for an existing seawater salt manufacturing device, the quadruplex effect vacuum evaporator shown in Figure 3, we can estimate the evaporation and condensation rates, i.e., the freshwater production rate, of this seawater desalination method using a liquid column and decompression boiling as follows.

In the quadruplex effect vacuum evaporator shown in Figure 3, steam at 120 $\left[{ }^{\circ} \mathrm{C}\right]$ and 2 [atm.] produced by a boiler is first introduced into the kettle 1 and it heats the seawater through a heat exchanger, producing steam at $100\left[{ }^{\circ} \mathrm{C}\right]$ and 1 [atm.]. At that time, some of the water evaporates from the seawater and then the douche is produced as a result of the increase in salinity. A similar process occurs in the second to fourth kettles, the pressure and temperature are decreased sequentially. The diameter and height of each can are approximately 5 $[\mathrm{m}]$ and $15[\mathrm{~m}]$, respectively. There are some seawater desalination plants using multiple effect vacuum evaporators.

Table 1 shows some results of the $1^{\text {st }}$ to $4^{\text {th }}$ kettles in Figure 3 . For example, 


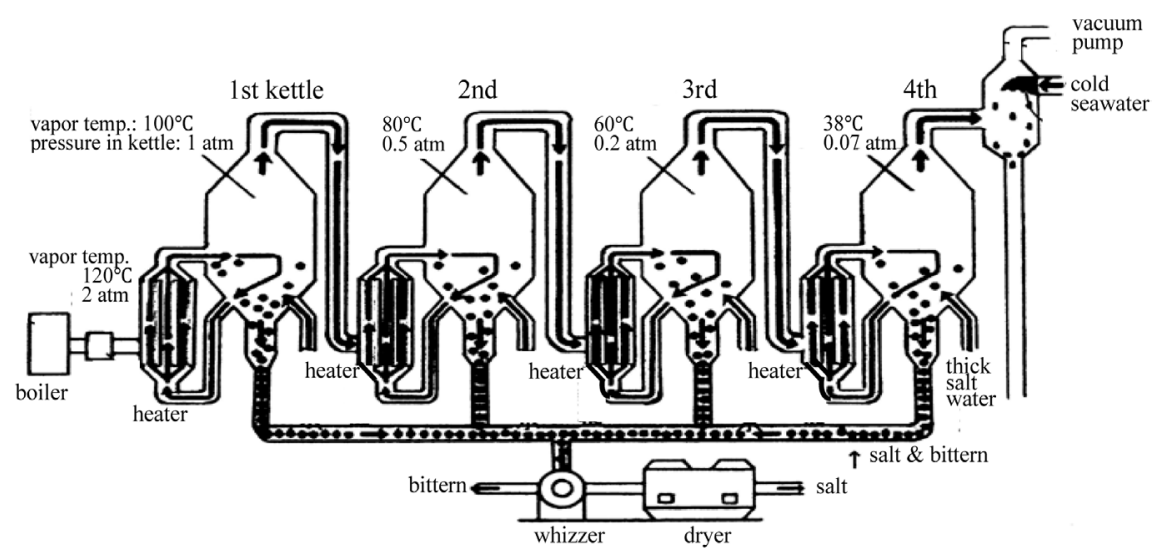

Figure 3. Quadruplex effect vacuum evaporator [Hashimoto (2004), Naikai Salt Ind. Co., Ltd., Japan (2008)].

Table 1. Evaporation rate [Hashimoto (2004), Naikai Salt Ind. Co., Ltd., Japan].

\begin{tabular}{cccccccc}
\hline Position & $1^{\text {st }}$ kettle & - & $2^{\text {nd }}$ & - & $3^{\text {rd }}$ & - & $4^{\text {th }}$ \\
\hline temperature $\left[{ }^{\circ} \mathrm{C}\right]$ & 100 & 94.4 & 80 & 64.6 & 60 & 41.2 & 38 \\
Pressure $[\mathrm{mmHg}]$ & 760 & 620 & 380 & 186 & 152 & 59 & 53.2 \\
evaporation rate $[\mathrm{t} / \mathrm{h}]$ & - & 42 & - & 40 & - & 37.8 & - \\
\hline
\end{tabular}

the evaporation rates of $1^{\text {st }}$ to $3^{\text {rd }}$ kettles are $42[\operatorname{ton} / \mathrm{h}], 40[$ ton $/ \mathrm{h}]$ and 37.8 $[$ ton $/ \mathrm{h}]$ at the temperature (and pressure) of $94.4\left[{ }^{\circ} \mathrm{C}\right](620[\mathrm{mmHg}]), 64.6\left[{ }^{\circ} \mathrm{C}\right]$ $(186[\mathrm{mmHg}])$ and $41.2\left[^{\circ} \mathrm{C}\right](59[\mathrm{mmHg}])$, respectively.

Figure 4 shows these results. The evaporation rate $T R$ decreases with decreasing the temperature $T_{s}$ from the $1^{\text {st }}$ to $3^{\text {rd }}$ kettles. The relationship between $T R[\mathrm{t} / \mathrm{h}]$ and $t_{s}\left[{ }^{\circ} \mathrm{C}\right]$ can be expressed by

$$
T R=21.55 t_{s}^{0.153}
$$

Calculating the evaporation rate of the fourth kettle with a diameter of $D=5$ [m] by Equation (3), we obtain $T R \approx 37.6[\mathrm{t} / \mathrm{h}]=31.9\left[\mathrm{~kg} /\left(\mathrm{m}^{2} \cdot \mathrm{min}\right)\right], p_{s t}=53.2$ [mmHg (abs.)], $t_{s}=38\left[{ }^{\circ} \mathrm{C}\right]$, and $T_{\text {sea }}=25\left[{ }^{\circ} \mathrm{C}\right]$.

In the case of Figure $2(\mathrm{~b})$, we obtain $T R \approx 36.3[\mathrm{t} / \mathrm{h}]=30.8\left[\mathrm{~kg} /\left(\mathrm{m}^{2} \cdot \mathrm{min}\right)\right], p_{s t}$ $=30[\mathrm{mmHg}$ (abs.) $]$, and $t_{s}=30\left[{ }^{\circ} \mathrm{C}\right], T_{\text {sea }}=25\left[{ }^{\circ} \mathrm{C}\right]$. In practice, the 50th kettle of a multi-stage flash distillation system of Hitachi Zosen Co., Japan is operating under the condition of $p_{s t}=38\left[\mathrm{mmHg}\right.$ (abs.)], $t_{s}=35\left[{ }^{\circ} \mathrm{C}\right]$, and $T_{\text {sea }}=31\left[{ }^{\circ} \mathrm{C}\right]$ (The Salt Industry of Japan, 2006).

In this study, a new desalination method and its associated equipment were presented and the feasibility of the new method was verified by the results of earlier experiments and the data from an actual desalination plant. Moreover, the new device operated at a low temperature, for example, $t_{s} \approx 38\left[{ }^{\circ} \mathrm{C}\right]$ or a lower one, approximately $30\left[{ }^{\circ} \mathrm{C}\right]$.

This new desalination method and associated equipment can be applied not only for seawater but also for waste water. The construction and operating costs expected to be lower than those of other desalination method because of the 


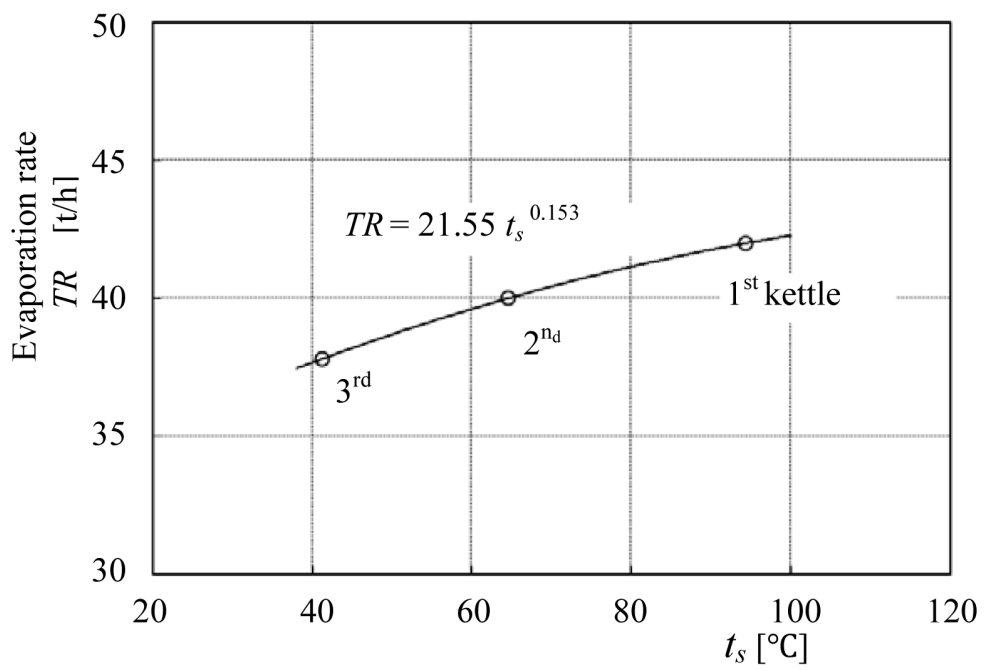

Figure 4. Evaporation rate [Hashimoto (2004), Naikai Salt Ind. Co., Ltd., Japan (2008)].

simple and rational arrangements. The details will be shown in the next study.

\section{Conclusions}

The major results are as follows.

1) A new desalination method and equipment by decompressed boiling and evaporation using liquid columns was proposed and the feasibility of the new method was verified by the results of earlier experiments and the data from an actual desalination plant.

The new desalination method, system, includes a heat exchanger, condenser in the head space of the seawater tower and the desalination can be automatically operated continuously.

2) The evaporation or condensation rate can be estimated as $T R \approx 37.6[\mathrm{t} / \mathrm{h}]=$ $31.9\left[\mathrm{~kg} /\left(\mathrm{m}^{2} \cdot \mathrm{min}\right)\right]$ under the operating conditions of the fourth kettle with a diameter of approximately $5[\mathrm{~m}]$, a pressure of $p_{s t} \approx 53.2[\mathrm{mmHg}$ (abs.)] and a temperature of $t_{s} \approx 38\left[{ }^{\circ} \mathrm{C}\right]$.

3) The new desalination method and device can be operated at a low temperature, for example $t_{s} \approx 38\left[{ }^{\circ} \mathrm{C}\right.$ ] or a lower one, approximately $30\left[{ }^{\circ} \mathrm{C}\right]$, can be applied not only for seawater but also for polluted or waste water, and will produce freshwater inexpensively compared to other seawater desalination methods because of the simple and rational arrangements.

\section{Acknowledgements}

In this study, many papers, documents and data were referred. I would like to express my appreciation to them.

\section{Conflicts of Interest}

The authors declare no conflicts of interest regarding the publication of this paper. 


\section{References}

[1] Hashimoto, H. (2004) Vacuum- and Pressurized-Salt Production Methods. Vol. 38, Encyclopedia Salt, Tobacco \& Salt Museum, The Salt Science Research Foundation, Japan. http://www.geocities.jp/t_hashimotoodawara/salt6/salt6-04-09.html

[2] Al-Kharabsheh, S. and Goswami, D.Y. (2003) Analysis of an Innovative Water Desalination System Sing Low-Grade Solar Heat. Desalination, 156, 323-332. https://doi.org/10.1016/S0011-9164(03)00363-1

[3] Gude, V.G. and Nirmalakhandan, N. (2009) Desalination at Low Temperatures and Low Pressure. Desalination, 244, 239-247. https://doi.org/10.1016/j.desal.2008.06.005

[4] Shalabh, C.M. and Goswami, D.Y. (2009) Theoretical Analysis of a Single-Stage and Two-Stage Solar Driven Flash Desalination System Based on Passive Vacuum Generation. Desalination, 249, 635-646.

[5] Shakouchi, T. (2014; 2011) Boiling Type Seawater Desalination Apparatus, and Method. Japanese Patent, No. 5398046B2.

[6] Naikai Salt Industries Co., Ltd. (2008) Technical Data.

[7] Water Reuse Promotion Center, Japan (2004) Desalination Technology Handbook.

[8] The Salt Industry Center of Japan (2006) Data Book for Seawater Science and Salt Production.

\section{Symbols}

$D$-diameter of kettle $[\mathrm{m}]$

$H_{L}$-latent heat $[\mathrm{kcal} / \mathrm{kg}]$

$H_{1}$-height of seawater column [m]

$\mathrm{H}_{2}$-height of freshwater column [m]

$p$-pressure $[\mathrm{kPa}]$ or $[\mathrm{mmHg}]$

$p_{s t}-$ saturation pressure in the top space, evaporation and condensation room $[\mathrm{kPa}]$ or $[\mathrm{mmHg}]$

$T R$-evaporation or condensation rate $[\mathrm{t} / \mathrm{h}]([$ ton/hour $])$

$T_{\text {sea }}$-seawater temperature $\left[{ }^{\circ} \mathrm{C}\right]$

$t$-temperature $\left[{ }^{\circ} \mathrm{C}\right]$

\section{Sub-Index}

$s$-saturation 